\title{
Alterations in EGF-Endocytosis, Lysosomal Enzyme Transport and Maturation of Cathepsins in Juvenile Neuronal Ceroid Lipofuscinosis Fibroblasts
}

\author{
Jaime Cárcel-Trullols*(i) \\ Laboratory of Cellular Biology, Centro de Investigación Príncipe Felipe, Valencia, Spain
}

\begin{abstract}
Background: Juvenile neuronal ceroid lipofuscinosis (JNCL), one of the most frequent forms of the NCL storage diseases, is known to be caused by loss-of-function mutations in ceroid-lipofuscinosis neuronal protein 3 (CLN3), but its cell function has not been fully elucidated. We previously reported increased lysosomal pH in CLN3 deficient cells. In the present study, we analysed the consequences of this effect in the endo-lysosomal pathways in CLN3 cells.

Methods: The present study investigated different endo-lysosomal pathways in control, CLN2, CLN3 human skin fibroblasts under high and low proteolysis conditions. Cell surface biotinylation after EGF $(2 \mathrm{ng} / \mathrm{mL}$ ) stimulation, EGF phosphorylation (Tyr-845), retromer and cation-independent mannose-6phosphate receptor (CI-MPR) levels and stability, EGF degradation pathways and cathepsin L and D levels were analysed by western blots. Caveolae mediated endocytosis was analysed by flow cytometry. CIMPR subcellular localization was ascertained by immunocytochemistry, confocal microscopy and further image analysis.

Results: Whereas caveolae-mediated endocytosis was not affected in CLN3 cells, clathrin-mediated epidermal growth factor (EGF) internalization was reduced, along with EGF receptor (EGFR) phosphorylation. In addition, cell surface EGFR levels and recycling to the cell membrane were increased. EGFR lysosomal degradation was impaired and our results suggest that the receptor was diverted to proteasomal degradation. We also analysed the machinery responsible for lysosomal hydrolase transport to the lysosome and found increased stability of CIMPR, a major receptor implicated in the transport of hydrolases. The subcellular distribution of the CI-MPR was also altered in CLN3 cells, since it accumulated within the Trans-Golgi network (TGN) and did not progress into the lysosomes. In addition, we found a reduced turnover of retromer subunits, a complex that retrieves the CI-MPR from endosomes to the TGN. Finally and as a possible consequence of these alterations in lysosomal enzyme transport, cathepsin L and D maturation were found suppressed in CLN3 cells.

Conclusion: Altogether, these results point to increased lisosomal $\mathrm{pH}$ as a pivotal event causing various alterations in intracellular traffic associated to the development of JNCL disease.

Keywords: Juvenile neuronal ceroid lipofuscinosis; Lysosomal pH; Clathrin mediated endocytosis; Caveolae-mediated endocytosis; Cathepsin L; Cathepsin D; Cl-MPR (Cl-MPR); Retromer; Epidermal Growth Factor Receptor.
\end{abstract}

Citation: Cárcel-Trullols J. Alterations in EGF-endocytosis, lysosomal enzyme transport and maturation of cathepsins in juvenile neuronal ceroid lipofuscinosis fibroblasts. Int Clin Neurosci J. 2020;7(1):6-15. doi:10.15171/icnj.2020.02.

*Correspondence to

Jaime Cárcel-Trullols,

Laboratory of Cellular Biology,

Centro de Investigación

Príncipe Felipe, Valencia,

Spain.

Email: jcartru@hotmail.com

Published online December 23, 2019

\section{Introduction}

Neuronal Ceroid Lipofuscinoses (NCLs) are the most common group of rare autosomal recessive neurodegenerative disorders of childhood. NCL are histologically characterized by the building up of autofluorescent pigments within lysosomes. Among the NCLs, the juvenile CLN3 disease, ${ }^{1,2}$ also known as juvenile NCL (JNCL) ${ }^{3}$ or Batten disease, ${ }^{4}$ is the most frequent. Increasing visual failure, seizures, motor and cognitive skill reduction, and early death are characteristic of JNCL. ${ }^{2}$ In more than $80 \%$ of patients with CLN3 deficient cells there is a $1.02 \mathrm{~kb}$ genomic DNA deletion in the CLN3 gene (CLN3) that predicts a non-functional protein. ${ }^{2}$ The CLN3-encoded protein (CLN3) is a highly conserved, multi-pass transmembrane glycoprotein that is confined to endosomes and lysosomes, ${ }^{5,6}$ but its precise cell role is still unknown. Studies in yeast have reported that BTN1, which encodes the ortholog of CLN3, is involved in the regulation of the vacuolar $\mathrm{pH}^{7-9}$ and the phospholipid contents of mitochondrial and vacuolar membranes. ${ }^{10}$ It was reported that in yeast, BTN2/CLN3 expression is up-regulated upon deletion of BTN1 the yeast ortholog of Hook1, a retromer accessory protein involved in retrieval of specific cargo from late endosomes to Golgi. ${ }^{11,12}$ Further

(C) 2020 The Author(s). This is an open access article distributed under the terms of the Creative Commons Attribution License (http:// creativecommons.org/licenses/by/4.0/), which permits unrestricted use, distribution, and reproduction in any medium, provided the original work is properly cited. 
studies in yeast concluded that BTN1 regulates retrograde sorting by mediating vesicle fusion through SNARE protein phosphorylation and assembly, which could be altered in JNCL. ${ }^{13}$

In mammalian cells, a role for CLN3 in endocytic trafficking has been proposed. ${ }^{14-17}$ Luiro et al showed that CLN3 overexpression in HeLa cells induces aggregation of Hook1, causing its dissociation from the microtubules in endosomal fusion events. ${ }^{14}$ They linked in CLN3 fibroblasts the observed abnormalities to a delay in the lysosomal delivery of low-density lipoprotein and to increased recycling rates of transferrin. ${ }^{14}$

Other studies using mammalian cells have also indicated that CLN3 is directly implicated in the regulation of lysosomal $\mathrm{pH}^{18}$ or in the delivery of lysosomal enzymes. ${ }^{19,20}$

Soluble acid hydrolases, once modified with mannose 6-phosphate residues in the Golgi, are commonly recognized by mannose 6-phosphate receptors and then transported to the endo/lysosomal system. ${ }^{21}$ For example, two of the main lysosomal cathepsins, D and $\mathrm{L}$, are transported by the cation-independent mannose 6-phosphate receptor (CI-MPR). ${ }^{22}$ Cathepsin D is known to degrade ATP synthase subunit $c$, which typically accumulates in CLN3 deficient cells. ${ }^{23}$ In lysosomes, cathepsin L has been found to cleave CLN7p, a protein deficient in a variant of the late-infantile NCL. ${ }^{24}$ Cathepsin $\mathrm{L}$ has also been localized in secretory vesicles containing neuropeptides and found to play an essential role in neurotransmitter production. ${ }^{25}$

Our previous studies indicated that lysosomal $\mathrm{pH}$ was increased in isolated cells from JNCL patients, resulting in reduced fusion of autophagosomes with lysosomes. ${ }^{26}$ In the present study, we further examined the consequences of increased $\mathrm{pH}$ in CLN3 cells in other lysosomal related processes. Throughout the text, CLN3-deficient cells will be referred to as CLN3 cells. Cells carrying the tpp1 mutation (CLN2 cells) have been used as control cells along with non-mutated cells (control cells). We report in these cells alterations in receptor-mediated endocytosis and in delivery of lysosomal cathepsins to lysosomes. Our data are consistent with the idea that increased lysosomal $\mathrm{pH}$ plays a central role in determining the phenotype of cells from JNCL patients.

\section{Results}

CLN3 cells have increased EGFR recycling

To examine receptor-mediated endocytosis, we analysed the phosphorylation state of the EGFR by Western blot and the rate of ligand endocytosis using EGF bound to Alexa Fluor 488 (AF488-EGF) by flow cytometry. To avoid possible aging effects, all experiments were done comparing cells at a similar passage number (10-14) in the cell culture. Upon ligand binding, EGFR phosphorylation increases at 5,10 and $15 \mathrm{~min}$ in CLN3 cells as compared to control cells (Figure 1A). On the contrary, internalization of EGF was similar in CLN3 and control cells (Figure 1B, left panel). Flow cytometry analysis of internalized BODIPY FL C5-Ceramide, a specific marker of caveolae-mediated endocytosis, ${ }^{27}$ shows that this type of internalization was not altered either in CLN3 fibroblasts as compared to controls (Figure 1B, right panel). However, plasma membrane composition
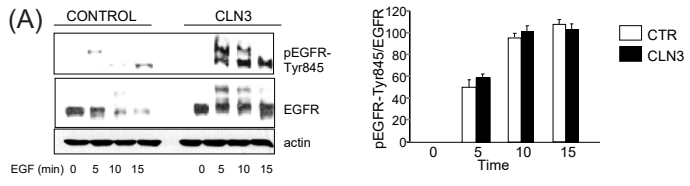

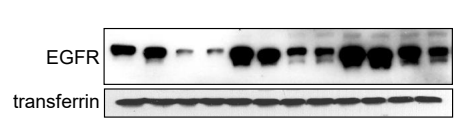

(C)

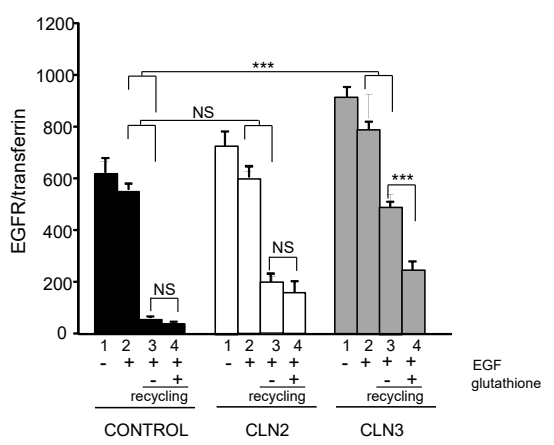

Figure 1. Alterations of EGF endocytosis in CLN3 cells. (A) Control and CLN3 fibroblasts were incubated with EGF (100 ng/mL) in high proteolysis medium for the indicated time periods. A representative blot of total cell extracts analysed with antibodies that recognize phosphorylated (Tyr845) EGFR and actin is shown. Bands were quantified and the ratios of EGFR to actin are shown below. (B) Comparison of EGF (left panel) or BODIPY FL C5-Ceramide (right panel) internalization in control, CLN2 and CLN3 fibroblasts incubated at $37^{\circ} \mathrm{C}$ with AF488-EGF ( $\left.200 \mathrm{ng} / \mathrm{mL}\right)$ or BODIPY FL C5-Ceramide (0.5 $\left.\mu \mathrm{M}\right)$, respectively, for the indicated times. After washing, measurements were carried out by flow cytometry as described in Materials and Methods and are shown as percentage of fluorescently labelled cells. (C) Exponentially growing control, CLN2 and CLN3 fibroblasts incubated in high proteolysis medium were surface biotinylated, stimulated with EGF $(2 \mathrm{ng} / \mathrm{mL})$ and treated with reduced glutathione as explained in Materials and Methods. Samples were pulled-down with NeutrAvidin agarose-beads and subsequently analyzed by immunoblotting using anti-EGFR and, as an internal control, anti-TfR antibodies. Representative blots are shown and EGFR bands from three independent experiments similar to those shown were densitometred and normalized to the corresponding transferrin bands. Data from three independent experiments are expressed in \% relative to cells at time 0 min. All results are the mean \pm SD from three separate experiments, with triplicated measurements, and stars indicate statistically significant differences from control values at each time point. 
is likely altered, as flow cytometry analysis revealed that binding to cholera toxin $\mathrm{B}(\mathrm{ChTxB})$, which binds to cell surface GM1 gangliosides, ${ }^{28}$ is severely impaired in CLN3 fibroblasts (Figure S1).

Next, we examined if EGFR recycling was altered in CLN3 fibroblasts in comparison to control and CLN2 fibroblasts by cell surface protein biotinylation, in nontreated cells (lane 1) and in cells treated with EGF at low (2 $\mathrm{ng} / \mathrm{mL}$ ) concentration and reduced glutathione $(50 \mathrm{mM})$; at such low EGF concentration, most of the receptor is recycled to the cell membrane. ${ }^{29}$ Internalized levels of biotinylated EGFR did not change among CLN3, CLN2, and control fibroblasts (lanes 1 and 2 in Figure 1C), in agreement with the observed similar EGF endocytosis. After subsequent treatment with EGF $(2 \mathrm{ng} / \mathrm{mL})$ and with reduced glutathione $(50 \mathrm{mM})$, EGFR levels decreased in CLN3 fibroblasts as compared to cells not treated with activated glutathione, but the corresponding levels did not change in control or CLN2 fibroblasts (lanes 3 and 4 in Figure 1C). This indicates that EGFR recycling was increased in CLN3 fibroblasts. Also, the comparison of biotinylated EGFR relative to transferrin levels in control versus CLN3 fibroblasts (lane 1) indicates, as expected, that cell surface levels of EGFR are increased in fibroblasts from JNCL patients.

Lysosomal degradation of EGFR is delayed and the receptor is diverted towards the proteasomal pathway in CLN3 fibroblasts

To further examine the EGFR endocytic pathway upon internalization, receptor levels were analysed by Western blot after incubation with EGF $(100 \mathrm{ng} / \mathrm{mL})$. At this high concentration of ligand, $90 \%$ of the receptor is headed towards degradation. ${ }^{29}$ Ligand-induced degradation of
EGFR was significantly delayed in the CLN3 fibroblasts as compared to their respective controls at all-time points (Figure 2A). As an increased lysosomal $\mathrm{pH}$ could prevent the receptor from being degraded in lysosomes, we examined the possibility that EGFR could undergo proteasomal degradation. Indeed, proteasome inhibition has also been shown to attenuate ligand-induced degradation of EGFR in HeLa cells. ${ }^{30}$ We thus analysed the relative contribution of lysosomal and proteasomal degradation pathways to degradation of EGFR in CLN3 cells. Inhibitors were added $4 \mathrm{~h}$ prior to EGF (100 ng/ $\mathrm{mL}$ ) treatment, and EGFR degradation was analysed by Western blot for 1 additional hour in the presence of the inhibitors and in high proteolysis medium to maximize degradation. In the presence of the proteasome inhibitor lactacystin, the difference in EGFR levels between CLN3 cells and control cells was increased by $45 \%$ as compared to the absence of inhibitors, but not in CLN2 cells (Figure $2 \mathrm{~B}$ and not shown). On the contrary, in the presence of the lysosomal inhibitors $\mathrm{NH}_{4} \mathrm{Cl}$ plus leupeptin the difference in EGFR levels decreased by $55 \%$ when compared with absence of inhibitors (Figure 2B). These results suggest that proteasome degradation of EGFR is increased in CLN3 fibroblasts, possibly as a compensatory mechanism for the impaired lysosomal degradation in these cells.

The observed variable steady-state EGFR levels in control and in CLN3 cells should not be affecting the described tendencies as similar results were obtained in cells with different EGFR levels (data not shown).

The stability of the Cl-MPR and of the retromer subunits is increased in CLN3 fibroblasts under high proteolysis conditions

Next, we examined levels and turnover in high and
A

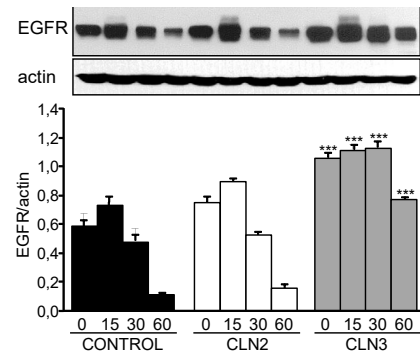

B

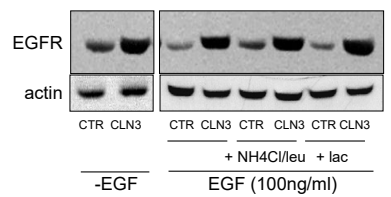

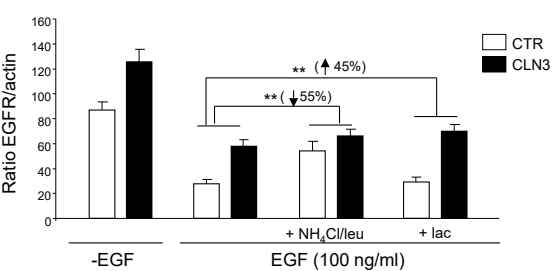

Figure 2. In CLN3 fibroblasts, EGFR degradation is diverted from the lysosomal to a proteasomal pathway. (A) Control and CLN3 fibroblasts were incubated for $60 \mathrm{~min}$ with EGF $(100 \mathrm{ng} / \mathrm{mL})$, and total extracts were analyzed by Western blot. Representative blots and quantification of EGFR levels by densitometry are shown. Data in the histogram are shown in percentage relative to time 0 . Stars indicate statistically significant differences from control values at each time point. (B) Control (CTR) and CLN3 fibroblasts were treated with EGF and with the inhibitors where indicated as described in the materials and methods section. Total extracts were immunoblotted with anti-EGFR and, as a loading control, anti-actin. A representative blot is shown. Bands corresponding to EGFR were quantified by densitometry and the ratios of EGFR to actin were plotted on the right. Stars indicate statistically significant differences in control and CLN3 fibroblasts treated with inhibitors from the corresponding values in the absence of inhibitors. 
low proteolysis media of the CI-MPR, a major receptor of soluble hydrolases that shuttles from the TGN to endosomes. Different medium conditions were used in these experiments for each cell type, as we wanted to observe differences under stressed (high proteolysis, $\mathrm{H}$ ) and non-stressed lysosomal enzyme transport (low proteolysis, L). In the presence of cycloheximide (CHX), CI-MPR stability was found increased in CLN3 fibroblasts compared to controls under both conditions (Figure 3A). To analyze if this was due to CI-MPR missorting, we also analyzed the levels of retromer subunits because retromer mediates endosome-to-TGN retrieval of the CI-MPR. ${ }^{31,32}$ Retromer is a pentameric complex which includes two sorting nexin family members (typically, SNX1 and SNX2), that curve the endosomal membrane, and three additional subunits, Vps26, Vps 29 and Vps 35, which constitute the complex core and determine cargo sorting. ${ }^{33}$ We found that the stability of retromer subunits Vps26 and Vps35 (Figure 3B) and SNX1 and SNX2 (Figure 3C) are increased in high and low proteolysis media in CLN3 fibroblasts. The increased stability of retromer under the studied conditions suggests impairment of endosome-toTGN retrieval and possible alterations in the delivery of lysosomal enzymes.

\section{Cl-MPR accumulates in TGN in CLN3 fibroblasts}

To explain the reduced turnover of the CI-MPR (along with retromer), we hypothesized that cycling of CI-MPR between TGN and early endosomes might be affected in the NCL cells. Thus, we compared the localization of CIMPR with that of the TGN-resident protein TGN46 ${ }^{34}$ by confocal microscopy. Both are transmembrane proteins that cycle back and forth from the TGN to the early endosomes, ${ }^{35}$ although most of TGN46 is maintained at the TGN at steady state, similarly to the CI-MPR. ${ }^{36,37}$ In CLN3 fibroblasts, CI-MPR colocalized with TGN46 in tubular TGN-like structures (Figure 4). According to our results CI-MPR would not function as a proper enzyme shuttle as it would not leave the TGN.

Processing of procathepsin $\mathrm{L}$ and $\mathrm{D}$ into cathepsin $\mathrm{L}$ and D is abrogated in CLN3 fibroblasts

Accumulation ofCI-MPRin TGN could affect the transport of acid hydrolases to the lysosome. Cathepsins L and D have been shown to be shuttled to the lysosomes mainly by CI-MPR. ${ }^{22}$ Therefore, we examined the processing of procathepsin L and D to their mature forms. Fibroblasts were cultured in high or low proteolysis medium as we wanted to observe differences under stressed (High proteolysis) and non-stressed lysosomal enzyme transport (Low proteolysis). Levels of procathepsin and cathepsin $\mathrm{L}$ and $\mathrm{D}$ were analysed by Western blot. We found that procathepsin $\mathrm{L}$ was not converted into cathepsin $\mathrm{L}$ in CLN3 fibroblasts (Figure 5). Processing of procathepsin D into cathepsin D was also affected in CLN 3 fibroblasts under the same conditions, but to a lesser extent (Figure
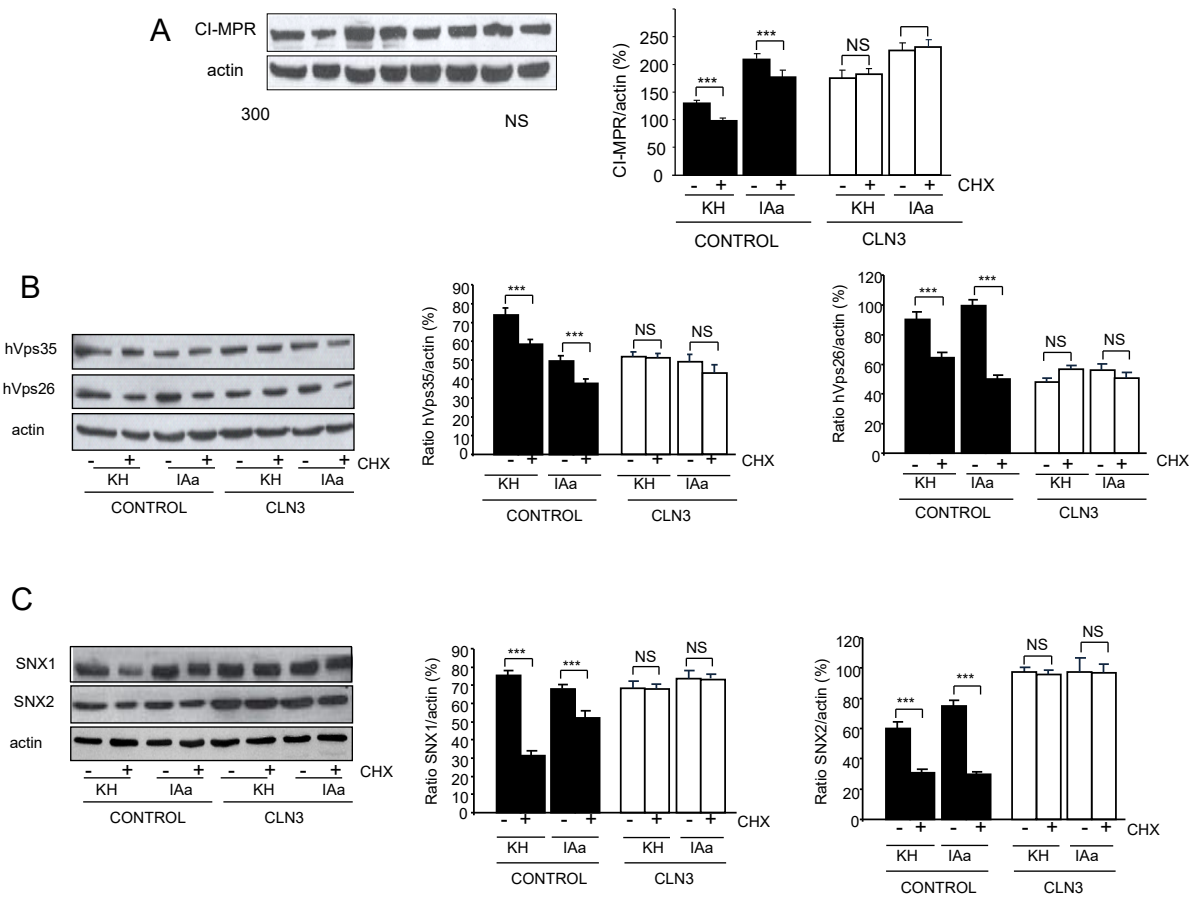

Figure 3. Increased stability of the CI-MPR and retromer subunits in CLN3 fibroblasts. Fibroblasts were incubated under high (H) or low (L) proteolysis conditions in the presence of cycloheximide $(\mathrm{CHX}, 100 \mu \mathrm{g} / \mathrm{mL}$ for $6 \mathrm{~h}$ ). Total extracts were immunoblotted with the following antibodies: (A) anti-Cl-MPR, (B) anti-hVps35 and anti-hVps26 and (C) anti-SNX1 and anti-SNX2. Anti-actin was used as a loading control. The bands that correspond to the analyzed proteins were quantified by densitometry and normalized to actin. Representative gels are shown and the histograms depict the corresponding protein/actin ratios. Stars indicate statistically significant differences between cycloheximide-treated and untreated fibroblasts. 

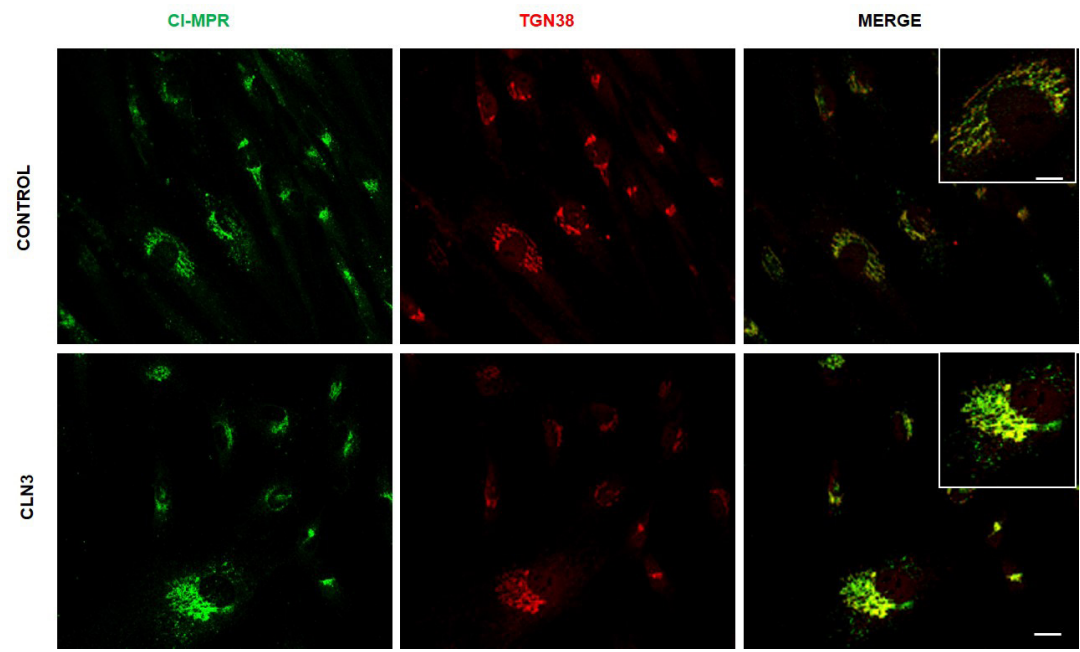

Figure 4. In CLN3 fibroblasts, CI-MPR accumulates in the TGN. Representative fluorescence microscopy images of control and CLN3 fibroblasts incubated at $37^{\circ} \mathrm{C}$ under high proteolysis conditions in the presence of lysosomal inhibitors, fixed, and probed with anti-Cl-MPR and anti-TGN46. Cells were examined by confocal microscope.

5). These results reflect the consequences of the shown alterations in the cell machinery responsible for TGN to endosome communication.

\section{Discussion}

In a previous report, we found that CLN3 cells, as opposed to CLN2 cells, had an increase of 0.5 units in lysosomal $\mathrm{pH}$ over normal (wild type) cells. ${ }^{26}$ The current study, using fibroblasts derived from Juvenile CLN3 patients (called CLN3 fibroblasts), analyzes the potential effects of this increased $\mathrm{pH}$ in EGFR traffic and lysosomal enzyme transport. EGFR/ligand dissociation and dissociation of the transported lysosomal enzymes from CI-MPR are both dependent on $\mathrm{pH} .{ }^{29,38}$ In this study, we conclude that EGFR degradation is impaired as a consequence of steady

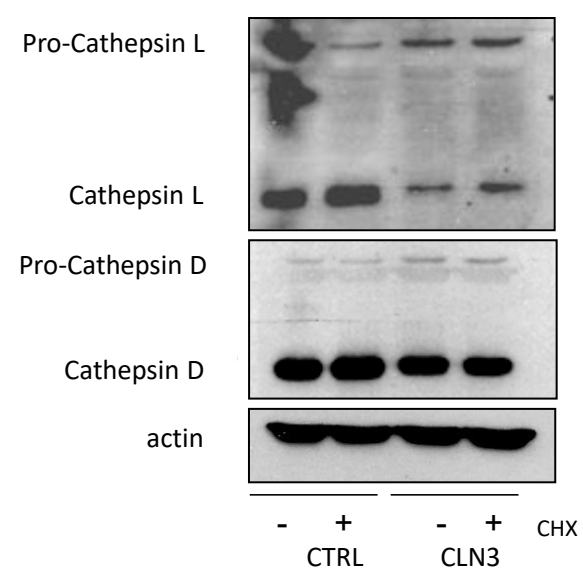

Figure 5. Processing of procathepsin $\mathrm{L}$ and $\mathrm{D}$ into the corresponding mature forms is impaired in CLN3 fibroblasts. Fibroblasts were incubated under high $(\mathrm{H})$ or low $(\mathrm{L})$ proteolysis conditions in the presence of cycloheximide (CHX, $100 \mu \mathrm{g} / \mathrm{ml}$ for $6 \mathrm{~h})$. Total extracts were immunoblotted with antibodies recognizing the precursor and mature forms of cathepsin D and cathepsin L, using actin as a loading control. recycling of the receptor to the cell surface. Furthermore, our results suggest that CI-MPR, the major lysosomal enzyme receptor, is also constantly recycled back from endosomes to the TGN, and, therefore, enzyme transport to lysosomes is altered.

EGFR auto phosphorylation, that occurs immediately after ligand binding, and is required for endocytic processing of the EGFR/ligand complex, ${ }^{39}$ was increased in CLN3 fibroblasts. Nevertheless, receptor-mediated endocytosis, that occurs immediately thereafter, was not affected. Once the EGFR/ligand complex arrives to the early endosomes, it can be recycled to the cell membrane or delivered to late endosomes and lysosomes for degradation. In HeLa cells, only $30 \%$ of the internalized EGFR is degraded at low $(1.5 \mathrm{ng} / \mathrm{mL})$ EGF concentrations, while most of it is recycled. However, at high (100 ng/ $\mathrm{mL}$ ) EGF concentrations, approximately $90 \%$ of the internalized receptor is degraded. ${ }^{31}$ In CLN3 cells, we found both increased recycling and impaired degradation of the EGFR at low and high concentrations of EGF, respectively. The increase in recycling could explain the increased amounts of EGFR at the cell membrane as well as the increase in receptor phosphorylation in the CLN3 cells. The decreased EGFR degradation could account for its higher steady state levels. Our results indicate that the internalized EGFR is not transported to lysosomes but is recycled back to the cell membrane in CLN3 cells.

Our results show that the CI-MPR - as well as subunits of the retromer complex, which mediates CI-MPR retrieval from endosomes to TGN - is more stable in CLN3 fibroblasts. The increased stability of CI-MPR and retromer levels might be a possible cell compensatory mechanism to try to preserve their altered functions. In accordance with our results, a role of the CLN3p in CIMPR traffic from the TGN has been already shown in HeLa cells with a transfected chimaeric CI-MPR reporter 
(CD8-CI-MPR) by Metcalf et al..$^{20}$ These authors found that ablation of CLN3p caused a 50\% reduction in exit of the CI-MPR reporter from the TGN. In accordance to our findings concerning CI-MPR stability, Qureshi et $\mathrm{a}^{40}$ showed in HeLa cells transfected with a plasmid expressing the a c.A959G mutant CLN5p, which has been physically and functionally related with the CLN3p, ${ }^{41,42}$ that mutant CLN5p was deficiently glycosylated and was abnormally detained in the endoplasmic reticulum resulting in reduced delivery to the endolysosomal compartment. Most of ours and the previously published work agree with the notion that impaired CLN3 function is related to altered trafficking and localization of CIMPR.

A failure in CI-MPR localization, as well as the inability to deliver its cargo to the endo-lysosomal compartment due to changes in $\mathrm{pH}$, could have a deep impact in delivery of lysosomal enzymes, such as cathepsins, whose precursors are transported by the CI-MPR..$^{22}$ Thus, Arighi et al observed that depletion of hVps26 by siRNA causes CI-MPR lysosomal degradation and reduced cathepsin D levels in HeLa cells. ${ }^{31}$ Similarly, Seaman showed a defect in cathepsin D maturation in HeLa cells after mVPS26 knock down in spite of seeing no effect in CI-MPR turnover. ${ }^{32}$ The study from Qureshi et al also showed a significant decrease in procathepsin $\mathrm{D}$ to cathepsin $\mathrm{D}$ conversion. ${ }^{40}$ A past study in Drosophila cells shows that retromer is needed for the right delivery of cathepsin L to lysosomes, but independently of the Drosophila homolog of the CI$\mathrm{MPR}^{43}$. Our results are consistent with these reports as we found mislocalized CI-MPR and deficient cathepsin D maturation in CLN3 cells. A recent study by CarcelTrullols et al further showed that in Baby Hamster Kidney cells, stably expressing myc-tagged human CLN3, activity of cathepsin D decreased as CLN3 expression increased under hyperosmolar conditions. ${ }^{44}$ Several studies in animal models have indicated that there are close ties between maturation and activity of cathepsin D and NCL disease. ${ }^{45-47}$ In addition, a reduction in the maturation of cathepsin D, which is known to degrade the subunit c of the ATP synthase, could explain its accumulation, a distinctive marker of the NCL phenotype. ${ }^{23}$ According to our results, the observed alterations in lysosomal enzyme transport in CLN3 cells are also reflected in a completely abrogated processing of procathepsin $\mathrm{L}$ into cathepsin L in CLN3 cells. Procathepsin L is mainly transported by the CI-MPR, although in neurons, SORLA/SORL1, an APP receptor which dysfunction is implicated in Alzheimer's disease, has also been involved in this process. ${ }^{48}$ Cathepsin $\mathrm{L}$ has been postulated as a central nervous system neuroprotease that participates in peptide neurotransmission and in neurodegenerative diseases, and expression of human cathepsin $\mathrm{L}$ has been found to prevent neuronal cell death and consequent neurodegeneration in cells of the cerebral cortex and in Purkinje cells of the cerebellum. ${ }^{49,50}$ An animal model with a combined deficiency in cathepsins B and L resulted in early-onset neurodegeneration in mice reminiscent of NCL in humans. ${ }^{50}$ Other reports suggest that cathepsin L may be linked to Parkinsonian neurodegeneration by means of 6-hydroxydopamine induced apoptosis..$^{51}$ Thus, the lack of procathepsin L maturation could be the linkage between lysosomal alterations and neurodegeneration.

In conclusion, the results presented in this study show that in juvenile CLN3 disease, increased lysosomal $\mathrm{pH}$ might be responsible for the reported alterations in EGFR recycling and degradation. Along with these alterations the showed CI-MPR mislocalization likely plays a very important role in the alterations of cathepsin $\mathrm{L}$ and $\mathrm{D}$ maturation that may critically affect JNCL and other types of related NCL diseases.

\section{Materials and Methods}

\section{Materials}

Minimum essential medium (MEM), human insulin, 3-methyladenine, $\mathrm{NH}_{4} \mathrm{Cl}$, PMSF, cycloheximide, EDTA, streptavidin, L-glutathione (reduced), anti-tubulin antibody and horseradish-peroxidase labelled secondary antibodies were purchased from Sigma Chemical Co. EZLink Sulfo-NHS-SS-Biotin and Biotinylation Kits (NHSSS-Biotin) were purchased from Thermo Fisher Scientific. MEM amino acids 50x, MEM non-essential amino acids 100x, penicillin, MEM vitamins, streptomycin, foetal bovine serum and recombinant human EGF (PHG0311) were supplied by Life Technologies. Leupeptin and lactacystin were acquired from Peptide Institute, Inc. Phosphospecific antibodies that recognize phosphorylated (Tyr-845)-EGFR (\#6963) were purchased from Cell Signalling. Specific antibodies that recognize total EGFR (ab2430), used in western blot experiments, and CI-MPR (ab2733) and TGN46 (ab16052), used in the immunofluorescence experiments, were purchased from Abcam. Rabbit polyclonal antibodies to human retromer subunits ${ }^{52}$ have been described previously. A polyclonal anti-CI-MPR antibody was obtained as a gift from Dr. B. Hoflack. AF488-EGF (E-13345), AF488-ChtxB (C34775), Alexa Fluor ${ }^{\circledR} 488$ goat anti-mouse IgG, IgM $(\mathrm{H}+\mathrm{L})(\mathrm{A}-10667)$ and Alexa Fluor $^{\circledR} 546$ goat anti-rabbit $\operatorname{IgG}(\mathrm{H}+\mathrm{L})$ (A-11010) were purchased from Molecular Probes-Life Technologies. Other reagents, such as $\mathrm{H}_{2} \mathrm{O}_{2}$, Bovine Serum Albumin (BSA), trichloroacetic acid (TCA), and Purpald (4-amino-3-hydrazino-5-mercapto1,2,4-triazole-3-thiol), were of the best analytical quality available.

\section{Cell Culture}

Control cells, CLN2, CLN3 human skin fibroblasts were obtained from the Coriell Institute for Medical Research (Camden, NJ, USA). Conditions for cell growth, cell viability and growth curves as well as high and low proteolysis conditions were described previously. ${ }^{26}$ 
Flow Cytometry

Determination by flow cytometry of clathrin-mediated endocytosis was performed essentially as described earlier $^{53}$ and caveolae-mediated endocytosis was performed as a modification of an existing protocol. ${ }^{54}$ Subconfluent fibroblasts were incubated at $37^{\circ} \mathrm{C}$ under high proteolysis conditions to maximize internalization for the indicated times in the presence of AF488-EGF (200 ng/mL) or BODIPY FL C5-Ceramide $(0.5 \mu \mathrm{M})$. Cells were then washed with cold PBS at $4^{\circ} \mathrm{C}$ and about $5 \times 10^{5}$ cells were immediately analyzed by flow cytometry (FACSCalibur flow cytometer from BD Biosciences). Cells were analyzed at excitation and emission wavelengths of 495 and $519 \mathrm{~nm}$, respectively, for the AF488-EGF experiment, and at $505 \mathrm{~nm}$ and 620, respectively, for the BODIPY FL C5-Ceramide determination. Mean fluorescence values were obtained, and the $\%$ of positive cells was calculated for every experimental condition.

To determine the binding of ChTxB and GM1 cell membrane contents, cells were incubated in a buffer containing ChTxB bound to Alexa Fluor-488 (AF488ChtxB) $(1 \mu \mathrm{g} / \mathrm{mL})$ in cold PBS containing sodium azide $(0.1 \%)$ at $4^{\circ} \mathrm{C}$ for one minute to prevent internalization, and then cells were washed three times in cold PBS containing sodium azide $(0.1 \%)$ at $4^{\circ} \mathrm{C}$. About $5 \times 10^{5}$ cells were immediately analyzed by flow cytometry (FACSCalibur flow cytometer, from BD Biosciences) at excitation and emission wavelengths of 495 and $519 \mathrm{~nm}$, respectively, and mean fluorescence values were plotted.

\section{Protein Determination and Western Blot}

These procedures have been already described. ${ }^{55}$ To determine protein degradation, cells were incubated for 6 hours with $100 \mu \mathrm{g} / \mathrm{mL}$ cycloheximide. All blots were developed using Lumi-Light Western Blotting Substrate and protein bands were quantified by densitometric analysis (Image Quant ECL, GE Healthcare).

For analysis of EGFR phosphorylation by immunoblot, cells were collected and lysed in lysis buffer (1\% Nonidet-P40, $0.5 \%$ sodium deoxycholate, $0.1 \%$ SDS, 50 mM Tris- $\mathrm{HCl}, 15 \%$ glycerol, $150 \mathrm{mM} \mathrm{NaCl}, 2 \mathrm{mM} \mathrm{Na}_{3} \mathrm{VO}_{4}$, $100 \mathrm{mM} \mathrm{NaF}, 20 \mathrm{mM} \mathrm{Na}_{4} \mathrm{P}_{2} \mathrm{O}_{7}, \mathrm{pH}$ 7.4, containing $1 \mathrm{mM}$ PMSF and $100 \mu \mathrm{M}$ leupeptin,) at $4^{\circ} \mathrm{C}$. Immunoblots were probed against phospho-specific EGFR and actin antibodies.

For semiquantitative determination of EGFR degradation, confluent fibroblasts were incubated at $37^{\circ} \mathrm{C}$ under high proteolysis conditions with or without EGF (100 ng/mL) for 15, 30 and 60 minutes. To inhibit protein degradation, cells were incubated $4 \mathrm{~h}$ before the addition of EGF with the lysosomal inhibitors $\mathrm{NH}_{4} \mathrm{Cl}(20$ $\mathrm{mM})$ and leupeptin $(100 \mu \mathrm{M})$, or with the proteasomal inhibitor lactacystin $(30 \mu \mathrm{M})$. Cells were then washed with cold PBS and homogenized in RIPA buffer (150 mM $\mathrm{NaCl}, 1 \%$ Nonidet P40, 0.5\% sodium deoxycholate, $0.1 \%$ SDS, $50 \mathrm{mM}$ Tris, $\mathrm{pH} 8.0$ ) containing $0.1 \mathrm{mM}$ leupeptin and $1 \mathrm{mM}$ PMSF. Extracts were centrifuged at 12,000 g for 10 minutes at $4^{\circ} \mathrm{C}$ and the supernatants were collected for Western blot. Lysates (50 $\mu \mathrm{g}$ protein) were analyzed on 15\% SDS-PAGE gels and proteins were transferred to PVDF membranes and probed with antibodies that recognize EGFR.

\section{Cell Surface Biotinylation}

The analysis of EGFR internalization and recycling was performed as described earlier. ${ }^{56}$ Briefly, confluent fibroblasts were washed three times with PBS-CM (containing $0.2 \mathrm{mM} \mathrm{CaCl}_{2}$ and $2 \mathrm{mM} \mathrm{MgCl}_{2}$ ) and incubated for $30 \mathrm{~min}$. in $\mathrm{PBS}-\mathrm{CM}$ at $4^{\circ} \mathrm{C}$ containing the biotin reagent (NHS-SS-Biotin) at $0.5 \mathrm{mg} / \mathrm{mL}$. A sample for each cell line was taken and frozen in RIPA buffer containing leupeptin $(0,1 \mathrm{mM})$ and PMSF (1 mM). After a first wash with PBS-CM to remove the excess of unbound reagent, and a second wash with MEM-BSA (MEM, $0.6 \%$ BSA, 20 mM Hepes- $\mathrm{NaOH}$ pH 7.4 and $0.35 \mathrm{~g} / \mathrm{L}$ $\mathrm{NaHCO}_{3}$ ), supplemented with $100 \mathrm{mM}$ glycine to quench the free succinimide groups, the cells were incubated at $37^{\circ} \mathrm{C}$ with $2 \mathrm{ng} / \mathrm{mL}$ EGF in MEM-BSA for 30 minutes. The ligand concentration used here was most suitable for semiquantitative determination of EGFR recycling. Afterwards, cells were incubated twice for two 20-minute periods in reduced glutathione at $50 \mathrm{mM}$ in TAPs buffer (50 mM TAPS-NaOH pH 8.60, $100 \mathrm{mM} \mathrm{NaCl}$ and 0.2 $\%$ BSA) and washed three times with ice cold PBS-CM. A sample for each cell line was taken and processed as above. The rest of the plates were incubated in PBS-CM containing iodoacetamide $(5 \mathrm{mg} / \mathrm{mL})$ for 5 minutes at $4^{\circ} \mathrm{C}$ to inactivate glutathione, and cells were washed with PBS-CM. EGF $2 \mathrm{ng} / \mathrm{mL}$ was added to the cells for 30 min., Cells were washed three times with PBS-CM and a sample for each cell line was frozen as before. Finally, cells were incubated again twice for two 20-minute periods in reduced glutathione at $50 \mathrm{mM}$ in TAPs buffer, washed three times with ice cold PBS-CM, and samples were frozen as detailed. Extracts from the different samples were centrifuged at $12000 \mathrm{~g}$ for 10 minutes, supernatants were collected, biotinylated proteins were pulled-down with NeutrAvidin beads and analyzed by immunoblotting using antibodies to EGFR and the transferrin receptor.

Immunocytochemistry, Confocal Microscopy and Image Analysis

Subconfluent fibroblasts were cultured for 4 hours on glass coverslips under high proteolysis conditions with protease inhibitors $(1 \mu \mathrm{M}$ pepstatin and $100 \mu \mathrm{M}$ leupeptin). Cells were then fixed for 10 minutes with $4 \%$ paraformaldehyde in PBS-CM. After quenching of the free aldehyde groups, cells were permeabilized, blocked, and incubated at $4^{\circ} \mathrm{C}$ overnight with anti-CI-MPR $(1: 100)$ and anti-TGN46 (1:200) to label the TGN. Secondary antibodies conjugated to Alexa 488 or to Alexa 595 were applied (1:500) for 1 hour at r.t. Slides were rinsed with 
PBS, mounted and observed in a confocal fluorescence microscope. For analysis of co-localization, cells were observed using a Leica TCS-SP2-AOBS confocal microscope using a $63 \mathrm{X}$ oil immersion objective of 1.4 NA at $1024 \times 1024$ pixel resolution.

The presented images were processed using Adobe Photoshop software (Adobe Systems) by adjusting brightness and contrast levels to the same extension for all the experimental conditions showed in each experiment.

\section{Statistics}

The presented data for the different conditions were calculated as means \pm S.D. of at least three independent experiments. GraphPad Prism version 5.0 software was used to perform statistical analysis. Two-tailed Student's $t$ tests was used to ascertain differences between paired samples and for multiple sample comparison one-way ANOVA was used followed by Student-Newman-Keuls post hoc test. The significance has been determined at ${ }^{*} P<0.05,{ }^{* *} P<0.01$ and ${ }^{* * *} P<0.005$, as showed in each case.

\section{Conclusion}

In the past two decades, considerable progress has been made in understanding the function of CLN3 protein in the development of the JNCL neurodegenerative disease. Despite knowing that CLN3p is an integral transmembrane glycoprotein that localizes to endosomes and lysosomes ${ }^{5,6}$ little is known about its precise function and its role in the development of the disease, so further investigation could set new molecular targets that could prevent the onset of this devastating neurodegenerative disease. Our group published in $2013^{26}$ that CLN3 cell lysosomes distinctively presented a statistically significantly increased $\mathrm{pH}$ of 0.5 units, possibly related to the reported defects in fluid phase endocytosis and impairment in autophagosome maturation in these cells. The presented study deepens in the study of the consequences of increased lysosomal $\mathrm{pH}$ in CLN3 cells as opposed to CLN2 and control cells. In this study we analyze the regulation of the endo-lysosomal pathways in CLN3 cells which might be directly affected by the increased lysosomal $\mathrm{pH}$. Clathrin-mediated epidermal growth factor (EGF) internalization showed to be reduced, possibly as consequence of impaired delivery of the receptor to the lysosomes, along with EGF receptor (EGFR) phosphorylation. Most importantly, EGFR lysosomal degradation was impaired and EGFR was rerouted to the cell membrane. We analysed the machinery responsible for lysosomal hydrolase transport to the lysosome and found increased stability of CI-MPR and the retromer subunits which are in charge of its retrieval from the endo-lysosomal system to the TGN, CI-MPR accumulation within the TGN and thus not progression into the lysosomal membranes as expected. Finally, as a possible consequence of these alterations in lysosomal enzyme transport, cathepsin $\mathrm{L}$ and $\mathrm{D}$ maturation were found dramatically reduced in CLN3 cells.

\section{Authors' contributions}

The entire manuscript was written by the author. The only author collected literature, designed and wrote the manuscript, edited and prepared manuscript for submission.

\section{Conflict of Interest Disclosures}

The authors declare that they have no conflict of interests.

\section{Ethical Statement}

Not applicable.

Availability of Supporting Data

Supporting data is available from the author.

\section{Funding}

This work was supported by the Spanish Ministry of Science and Innovation (BFU2011-22630), and the Centro de Investigación Biomédica en Red de Enfermedades Raras (CIBERER). The funders had no role in study design, data collection and analysis, decision to publish, or preparation of the manuscript.

\section{Acknowledgments}

I thank Asunción Montaner, Nuria Mas, Erwin Knecht, Carmen Aguado, Jose Manuel Vidal-Donet, Marcel Vergés and Alicia Martínez for technical assistance. I am also grateful to Dr. Carol R. Haft (NIH, Bethesda, USA) and Dr. Juan Bonifacino (NIH, Bethesda, USA), for supplying antibodies against retromer subunits, to Dr. B. Hoflack (Technische Universität Dresden, Dresden, Germany) for the antibody against $\mathrm{Cl}-\mathrm{MPR}$ and to the confocal microscopy and the flow cytometry facilities of the Centro de Investigación Príncipe Felipe.

\section{Supplementary Materials}

Supplementary file 1 contains Figure S1.

\section{References}

1. Williams RE, Mole SE. New nomenclature and classification scheme for the neuronal ceroid lipofuscinoses. Neurology. 2012;79(2):183-91. doi: 10.1212/WNL.0b013e31825f0547.

2. Isolation of a novel gene underlying Batten disease, CLN3. The International Batten Disease Consortium. Cell. 1995;82(6):949-57. doi: 10.1016/0092-8674(95)90274-0.

3. Kwon JM, Adams H, Rothberg PG, Augustine EF, Marshall FJ, Deblieck EA, et al. Quantifying physical decline in juvenile neuronal ceroid lipofuscinosis (Batten disease). Neurology. 2011;77(20):1801-7. doi: 10.1212/WNL.0b013e318237f649.

4. Cooper JD. Moving towards therapies for juvenile Batten disease? Exp Neurol. 2008;211(2):329-31. doi: 10.1016/j. expneurol.2008.02.016.

5. Järvelä I, Sainio M, Rantamäki T, Olkkonen VM, Carpén O, Peltonen L, et al. Biosynthesis and intracellular targeting of the CLN3 protein defective in Batten disease. Hum Mol Genet. 1998;7(1):85-90. doi: 10.1093/hmg/7.1.85.

6. Storch S, Pohl S, Quitsch A, Falley K, Braulke T. C-terminal prenylation of the CLN3 membrane glycoprotein is required for efficient endosomal sorting to lysosomes. Traffic. 2007;8(4):431-44. doi: 10.1111/j.1600-0854.2007.00537.x.

7. Pearce DA, Ferea T, Nosel SA, Das B, Sherman F. Action of BTN1, the yeast orthologue of the gene mutated in Batten disease. Nat Genet. 1999;22(1):55-8. doi: 10.1038/8861.

8. Chattopadhyay S, Muzaffar NE, Sherman F, Pearce DA. The yeast model for batten disease: mutations in BTN1, BTN2, and HSP30 alter pH homeostasis. J Bacteriol. 2000;182(22):641823. doi: 10.1128/jb.182.22.6418-6423.2000. 
9. Gachet Y, Codlin S, Hyams JS, Mole SE. btn1, the Schizosaccharomyces pombe homologue of the human Batten disease gene CLN3, regulates vacuole homeostasis. J Cell Sci. 2005;118(Pt 23):5525-36. doi: 10.1242/jcs.02656.

10. Padilla-López S, Langager D, Chan $\mathrm{CH}$, Pearce DA. BTN1, the Saccharomyces cerevisiae homolog to the human Batten disease gene, is involved in phospholipid distribution. Dis Model Mech. 2012;5(2):191-9. doi: 10.1242/dmm.008490.

11. Kama R, Robinson M, Gerst JE. Btn2, a Hook1 ortholog and potential Batten disease-related protein, mediates late endosome-Golgi protein sorting in yeast. Mol Cell Biol. 2007;27(2):605-21. doi: 10.1128/mcb.00699-06.

12. Richardson SC, Winistorfer SC, Poupon V, Luzio JP, Piper RC. Mammalian late vacuole protein sorting orthologues participate in early endosomal fusion and interact with the cytoskeleton. Mol Biol Cell. 2004;15(3):1197-210. doi: 10.1091/mbc.e03-06-0358.

13. Kama R, Kanneganti V, Ungermann C, Gerst JE. The yeast Batten disease orthologue Btn1 controls endosome-Golgi retrograde transport via SNARE assembly. J Cell Biol. 2011;195(2):203-15. doi: 10.1083/jcb.201102115.

14. Luiro K, Yliannala K, Ahtiainen L, Maunu H, Järvelä I, Kyttälä A, et al. Interconnections of CLN3, Hook1 and Rab proteins link Batten disease to defects in the endocytic pathway. Hum Mol Genet. 2004;13(23):3017-27. doi: 10.1093/hmg/ddh321.

15. Uusi-Rauva K, Kyttälä A, van der Kant R, Vesa J, Tanhuanpää K, Neefjes J, et al. Neuronal ceroid lipofuscinosis protein CLN3 interacts with motor proteins and modifies location of late endosomal compartments. Cell Mol Life Sci. 2012;69(12):2075-89. doi: 10.1007/s00018-011-0913-1.

16. Persaud-Sawin DA, McNamara JO, 2nd, Rylova S, Vandongen A, Boustany RM. A galactosylceramide binding domain is involved in trafficking of CLN3 from Golgi to rafts via recycling endosomes. Pediatr Res. 2004;56(3):449-63. doi: 10.1203/01.pdr.0000136152.54638.95.

17. Cao Y, Staropoli JF, Biswas S, Espinola JA, MacDonald $\mathrm{ME}$, Lee JM, et al. Distinct early molecular responses to mutations causing vLINCL and JNCL presage ATP synthase subunit $\mathrm{C}$ accumulation in cerebellar cells. PLoS One. 2011;6(2):e17118. doi: 10.1371/journal.pone.0017118.

18. Appu AP, Bagh MB, Sadhukhan T, Mondal A, Casey S, Mukherjee $A B$. Cln3-mutations underlying juvenile neuronal ceroid lipofuscinosis cause significantly reduced levels of Palmitoyl-protein thioesterases-1 (Ppt1)-protein and Ppt1-enzyme activity in the lysosome. J Inherit Metab Dis. 2019;42(5):944-54. doi: 10.1002/jimd.12106.

19. Fossale E, Wolf P, Espinola JA, Lubicz-Nawrocka T, Teed AM, Gao $\mathrm{H}$, et al. Membrane trafficking and mitochondrial abnormalities precede subunit c deposition in a cerebellar cell model of juvenile neuronal ceroid lipofuscinosis. BMC Neurosci. 2004;5:57. doi: 10.1186/1471-2202-5-57.

20. MetcalfDJ, Calvi AA, Seaman M, Mitchison HM, Cutler DF. Loss of the Batten disease gene CLN3 prevents exit from the TGN of the mannose 6-phosphate receptor. Traffic. 2008;9(11):190514. doi: 10.1111/j.1600-0854.2008.00807.x.

21. Braulke T, Bonifacino JS. Sorting of lysosomal proteins. Biochim Biophys Acta. 2009;1793(4):605-14. doi: 10.1016/j. bbamcr.2008.10.016.

22. Qian M, Sleat DE, Zheng H, Moore D, Lobel P. Proteomics analysis of serum from mutant mice reveals lysosomal proteins selectively transported by each of the two mannose 6-phosphate receptors. Mol Cell Proteomics. 2008;7(1):5870. doi: 10.1074/mcp.M700217-MCP200.

23. Kominami AE. What are the requirements for lysosomal degradation of subunit $\mathrm{c}$ of mitochondrial ATPase? IUBMB Life. 2002;54(2):89-90. doi: 10.1080/15216540214307.
24. Steenhuis P, Froemming J, Reinheckel T, Storch S. Proteolytic cleavage of the disease-related lysosomal membrane glycoprotein CLN7. Biochim Biophys Acta. 2012;1822(10):1617-28. doi: 10.1016/j.bbadis.2012.05.015.

25. Hook V, Funkelstein L, Wegrzyn J, Bark S, Kindy M, Hook G. Cysteine Cathepsins in the secretory vesicle produce active peptides: Cathepsin L generates peptide neurotransmitters and cathepsin B produces beta-amyloid of Alzheimer's disease. Biochim Biophys Acta. 2012;1824(1):89-104. doi: 10.1016/j. bbapap.2011.08.015.

26. Vidal-Donet JM, Cárcel-Trullols J, Casanova B, Aguado C, Knecht E. Alterations in ROS activity and lysosomal $\mathrm{pH}$ account for distinct patterns of macroautophagy in LINCL and JNCL fibroblasts. PLoS One. 2013;8(2):e55526. doi: 10.1371/ journal.pone.0055526.

27. Marks DL, Bittman R, Pagano RE. Use of Bodipy-labeled sphingolipid and cholesterol analogs to examine membrane microdomains in cells. Histochem Cell Biol. 2008;130(5):81932. doi: 10.1007/s00418-008-0509-5.

28. O'Keefe E, Cuatecasas P. Cholera toxin and membrane gangliosides: binding and adenylate cyclase activation in normal and transformed cells. J Membr Biol. 1978;42(1):6179. doi: 10.1007/bf01870394.

29. Sigismund S, Argenzio E, Tosoni D, Cavallaro E, Polo S, Di Fiore PP. Clathrin-mediated internalization is essential for sustained EGFR signaling but dispensable for degradation. Dev Cell. 2008;15(2):209-19. doi: 10.1016/j.devcel.2008.06.012.

30. Kesarwala AH, Samrakandi MM, Piwnica-Worms D. Proteasome inhibition blocks ligand-induced dynamic processing and internalization of epidermal growth factor receptor via altered receptor ubiquitination and phosphorylation. Cancer Res. 2009;69(3):976-83. doi: 10.1158/0008-5472.can-08-2938.

31. Arighi CN, Hartnell LM, Aguilar RC, Haft CR, Bonifacino JS. Role of the mammalian retromer in sorting of the cationindependent mannose 6-phosphate receptor. J Cell Biol. 2004;165(1):123-33. doi: 10.1083/jcb.200312055.

32. Seaman MN. Cargo-selective endosomal sorting for retrieval to the Golgi requires retromer. J Cell Biol. 2004;165(1):11122. doi: 10.1083/jcb.200312034.

33. Vergés M1. Retromer: multipurpose sorting and specialization in polarized transport. Int Rev Cell Mol Biol. 2008;271:15398. doi: 10.1016/s1937-6448(08)01204-5.

34. Banting G, Ponnambalam S. TGN38 and its orthologues: roles in post-TGN vesicle formation and maintenance of TGN morphology. Biochim Biophys Acta. 1997;1355(3):209-17. doi: 10.1016/s0167-4889(96)00146-2.

35. Lieu ZZ, Derby MC, Teasdale RD, Hart C, Gunn P, Gleeson PA. The golgin GCC88 is required for efficient retrograde transport of cargo from the early endosomes to the trans-Golgi network. Mol Biol Cell. 2007;18(12):4979-91. doi: 10.1091/ mbc.e07-06-0622.

36. Ghosh RN, Mallet WG, Soe TT, McGraw TE, Maxfield FR. An endocytosed TGN38 chimeric protein is delivered to the TGN after trafficking through the endocytic recycling compartment in CHO cells. J Cell Biol. 1998;142(4):923-36. doi: 10.1083/ jcb.142.4.923.

37. Lin SX, Mallet WG, Huang AY, Maxfield FR. Endocytosed cation-independent mannose 6-phosphate receptor traffics via the endocytic recycling compartment en route to the trans-Golgi network and a subpopulation of late endosomes. Mol Biol Cell. 2004;15(2):721-33. doi: 10.1091/mbc.e03-070497.

38. Bonifacino JS, Rojas R. Retrograde transport from endosomes to the trans-Golgi network. Nat Rev Mol Cell Biol. 2006;7(8):568-79. doi: 10.1038/nrm1985. 
39. Sorkin A, Waters C, Overholser KA, Carpenter G. Multiple autophosphorylation site mutations of the epidermal growth factor receptor. Analysis of kinase activity and endocytosis. J Biol Chem. 1991;266(13):8355-62.

40. Qureshi YH, Patel VM, Berman DE, Kothiya MJ, Neufeld JL, Vardarajan B, et al. An Alzheimer's Disease-Linked Loss-ofFunction CLN5 Variant Impairs Cathepsin D Maturation, Consistent with a Retromer Trafficking Defect. Mol Cell Biol. 2018;38(20). doi: 10.1128/mcb.00011-18.

41. Vesa J, Chin MH, Oelgeschlager K, Isosomppi J, DellAngelica EC, Jalanko A, et al. Neuronal ceroid lipofuscinoses are connected at molecular level: interaction of CLN5 protein with CLN2 and CLN3. Mol Biol Cell. 2002;13(7):2410-20. doi: 10.1091/mbc.e02-01-0031.

42. Huber RJ, Mathavarajah S. Secretion and function of Cln5 during the early stages of Dictyostelium development. Biochim Biophys Acta Mol Cell Res. 2018;1865(10):1437-50. doi: 10.1016/j.bbamcr.2018.07.017.

43. Maruzs T, Lőrincz P, Szatmári Z, Széplaki S, Sándor Z, Lakatos $Z$, et al. Retromer Ensures the Degradation of Autophagic Cargo by Maintaining Lysosome Function in Drosophila. Traffic. 2015;16(10):1088-107. doi: 10.1111/tra.12309.

44. Cárcel-Trullols J, Kovács AD, Pearce DA. Role of the Lysosomal Membrane Protein, CLN3, in the Regulation of Cathepsin D Activity. J Cell Biochem. 2017;118(11):3883-90. doi: 10.1002/jcb.26039.

45. Awano T, Katz ML, O'Brien DP, Taylor JF, Evans J, Khan $\mathrm{S}$, et al. A mutation in the cathepsin $\mathrm{D}$ gene (CTSD) in American Bulldogs with neuronal ceroid lipofuscinosis. Mol Genet Metab. 2006;87(4):341-8. doi: 10.1016/j. ymgme.2005.11.005.

46. Wavre-Shapton ST, Calvi AA, Turmaine M, Seabra MC, Cutler DF, Futter CE, et al. Photoreceptor phagosome processing defects and disturbed autophagy in retinal pigment epithelium of Cln3Deltaex1-6 mice modelling juvenile neuronal ceroid lipofuscinosis (Batten disease). Hum Mol Genet. 2015;24(24):7060-74. doi: 10.1093/hmg/ddv406.

47. Koike M, Nakanishi H, Saftig P, Ezaki J, Isahara K, Ohsawa $\mathrm{Y}$, et al. Cathepsin D deficiency induces lysosomal storage with ceroid lipofuscin in mouse CNS neurons. J Neurosci. 2000;20(18):6898-906.

48. Canuel M, Libin Y, Morales CR. The interactomics of sortilin: an ancient lysosomal receptor evolving new functions. Histol Histopathol. 2009;24(4):481-92. doi: 10.14670/hh-24.481.

49. Felbor U, Kessler B, Mothes W, Goebel HH, Ploegh HL, Bronson RT, et al. Neuronal loss and brain atrophy in mice lacking cathepsins B and L. Proc Natl Acad Sci U S A. 2002;99(12):7883-8. doi: 10.1073/pnas.112632299.

50. Sevenich L, Pennacchio LA, Peters C, Reinheckel T. Human cathepsin $\mathrm{L}$ rescues the neurodegeneration and lethality in cathepsin $\mathrm{B} / \mathrm{L}$ double-deficient mice. Biol Chem. 2006;387(7):885-91. doi: 10.1515/bc.2006.112.

51. Xiang B, Fei X, Zhuang W, Fang Y, Qin Z, Liang Z. Cathepsin $\mathrm{L}$ is involved in 6-hydroxydopamine induced apoptosis of $\mathrm{SH}$ SY5Y neuroblastoma cells. Brain Res. 2011;1387:29-38. doi: 10.1016/j.brainres.2011.02.092.

52. Haft CR, de la Luz Sierra M, Bafford R, Lesniak MA, Barr VA, Taylor SI. Human orthologs of yeast vacuolar protein sorting proteins Vps26, 29, and 35: assembly into multimeric complexes. Mol Biol Cell. 2000;11(12):4105-16. doi: 10.1091/mbc.11.12.4105.

53. Göstring L, Chew MT, Orlova A, Höidén-Guthenberg I, Wennborg A, Carlsson J, et al. Quantification of internalization of EGFR-binding Affibody molecules: Methodological aspects. Int J Oncol. 2010;36(4):757-63. doi: 10.3892/ijo_00000551.

54. Lauer S, Goldstein B, Nolan RL, Nolan JP. Analysis of cholera toxin-ganglioside interactions by flow cytometry. Biochemistry. 2002;41(6):1742-51. doi: 10.1021/bi0112816.

55. Martin de Llano JJ, Andreu EJ, Pastor A, de la Guardia M, Knecht E. Electrothermal atomic absorption spectrometric diagnosis of familial hypercholesterolemia. Anal Chem. 2000;72(11):2406-13. doi: 10.1021/ac991287p.

56. Gao YS, Hubbert CC, Yao TP. The microtubule-associated histone deacetylase 6 (HDAC6) regulates epidermal growth factor receptor (EGFR) endocytic trafficking and degradation. J Biol Chem. 2010;285(15):11219-26. doi: 10.1074/jbc. M109.042754. 